\title{
A new approach to the structure-properties relationship evaluation for porous polymer composites
}

\author{
Miroslav Černý ${ }^{~}$ Josef Petruš ${ }^{1,2}$ (D) František Kučera ${ }^{1}$ - Veronika Pavliňáková ${ }^{2} \cdot$ Vojtěch Kupka $^{3}$ Petr Poláček ${ }^{2}$. \\ Ivana Chamradová ${ }^{2}$
}

Received: 22 November 2019 / Accepted: 10 March 2020 / Published online: 13 March 2020

(c) Springer Nature Switzerland AG 2020

\begin{abstract}
In proposed study the effect of the composition and structure of polyurethane/ground rubber (PUR/GR) composites on the mechanical behavior was evaluated. The structure-properties relationship was studied for PUR matrices with different polarity, porosity and mechanical properties. The morphology of PUR/GR composites was expressed by two structural parameters-interspace filling and interspace volume. Experimental data of mechanical testing were fitted by powerlaw functions containing mentioned structural parameters whereas exponents of these parameters reflect differences in mechanical properties and chemical composition of PUR matrices. Obtained equations describe the mechanical behavior with respect to the structure and morphology of porous PUR/GR composites consisting of one filler and different PUR matrices. Proposed study suggests new approach to the description of the relationship between mechanical behavior and structure of porous composite materials.
\end{abstract}

Keywords Polymer composite $\cdot$ Reinforcement $\cdot$ Porosity $\cdot$ Mechanical properties

\section{Introduction}

In last few decades an effort of researchers is focused on the study of the structure-properties relationship for polymeric and composite materials. These activities are practiced for the prediction of material properties according to the material composition and for the preparation of tailormade materials with predictable properties. As presented in our study, the porosity is one of the parameters affecting (positively or negatively) the properties of natural and synthetic materials such as deformation strain, degradation rate, density, heat conductivity, etc.

Generally, porosity may occur in both one-component (e.g. polyurethane foams, metals, ceramic) and multi-component materials (e.g. wood, concrete, mineral castings). Recently, many researchers have attempted to examine the effect of porosity on material behavior, especially for one-component materials such as ceramics [1-11], natural materials [12], sintered metals $[1,9,13-15]$ and polymers $[1,16]$. The main effort has been developed in the field of mechanical properties mostly represented by elastic modulus and strength. A lot of published relationships between porosity and mechanical properties have been proposed for one-component materials in the form of linear $[1-3,6-8,12,15]$, exponential $[1,2,7,8,10]$, power $[1,2,5,7-9,11,13,14,16-18]$ and logarithmic functions [15]. The effect of porosity in one-component polymeric materials is well examined issue. Drozdov and Christiansend reported the decrease of Young's modulus with the increasing extent of porosity for different thermoplastic foams [19]. The similar relation between

$\triangle$ Josef Petruš, josef.petrus@ceitec.vutbr.cz| ${ }^{1}$ Institute of Materials Chemistry, Faculty of Chemistry, Brno University of Technology, Purkyňova 464/118, 61200 Brno, Czech Republic. ${ }^{2}$ Central European Institute of Technology, Brno University of Technology, Purkyňova 656/123, 61200 Brno, Czech Republic. ${ }^{3}$ Department of Physical Chemistry, Faculty of Science, Palacký University Olomouc, tř. 17. Listopadu 1192/12, 77146 Olomouc, Czech Republic. 
porosity and hardness of thermoplastic polyurethanes was evidenced by Prasad et al. [20].

Except of one-component materials, multi-component materials (composites) have been also under interest of researcher's community. Hong-Liang et al. has developed the Halpin-Tsai model which is applicable for composites containing short fibers [21] while Griffith's model can applied for the description of the fracture behavior of concrete representing multi-component porous material [15, 22]. The effect of the porosity on the mechanical behavior of polymer composites is under the interest of many researchers. For example, Hakim et al. [23] reported the influence of porosity on the interlaminar fracture behavior in carbon-fiber-reinforced polymer composites. Specifically, the increase of porosity led to the decrease in both interlaminar fracture toughness and thermal conductivity. In addition, the relationship between fracture mechanism and mechanical properties was described and affected by porosity. On the other hand, some properties can be improved by inducing porosity especially in the electronic [24, 25] or medical applications [26].

According to cited articles, the influence of structural parameters on mechanical properties is usually studied only for certain type of materials with similar chemical composition. For this reason, there are many individual expressions with an absence of universal solution for the determination of the relationship between structural parameters and mechanical properties of composite materials. In contrast, the objective of this work is to approach the experimentally obtained universal relationship between the structure and mechanical behavior of porous filled polymer composites. Proposed approaching is based on the structure-property relationship for one-component materials given by Eq. (1)

$z=z_{m} \cdot(1-n)^{b}$

where $z$ is mechanical property of porous material (e.g. elastic modulus $E$, strength $\sigma$, etc.), $z_{m}$ is mechanical property of nonporous material, $n$ is porosity and $b$ is an empirical constant.

In accordance with our previously published work [27], interspace filling parameter $\left(n_{p}\right)$ was included in our concept as a key parameter defining the amount of PUR matrix filling the volume between GR particles. $n_{p}$ can be calculated according to Eq. (2)

$n_{p}=\left(1-\frac{n}{n+v_{m}}\right)=\left(1-\frac{n}{n+\frac{v_{m(t)}}{1+\frac{n}{1-n}}}\right)$ where $v_{m}$ is volume fraction of matrix and $v_{m(t)}$ is volume fraction of matrix in theoretical nonporous material with the same composition. This parameter can be expressed also for one-component material as $(1-n)$.

Combination of Eqs. (1) and (2) results in the Eq. (3) calculating mechanical properties of porous composites:

$z_{c}=z_{m} \cdot n_{p}^{b}$

where $Z_{c}$ and $Z_{m}$ represent mechanical properties of porous composite and nonporous matrix, respectively. Exponent $b$ can be derived by fitting of experimentally measured data. Since the relation between exponent $b$ and mechanical properties of nonporous matrix was found to be more or less indicative, new structural parameterinterspace volume $\left(1-v_{f}\right)$-was included for more precise description of mechanical behavior of porous composites. $\left(1-v_{f}\right)$ represents the volume of material filled by matrix and porosity and can be calculated according to Eq. (4)

$1-v_{f}=n+v_{m}=n+n \cdot \frac{n_{p}}{1-n_{p}}=n \cdot\left(1+\frac{n_{p}}{1-n_{p}}\right)$

where $v_{f}$ is volume fraction of filler.

The structural parameters $n_{p}$ and $\left(1-v_{f}\right)$ seem to be key part in proposed research for better linkage between the structure and properties of composites. With using mentioned structural parameters and experimentally derived exponents, mechanical properties (i.e. tensile modulus, ultimate tensile strength, strain and energy need for ultimate strength achievement) can be predicted and linked to the structure and composition of multi-phase composites. Proposed model can be applied for the prediction of mechanical behavior of porous composite materials regarding the mechanical properties of individual components (matrix, fibers, filler, additives, etc.). Based on the obtained relationships, material properties could be tailored depending on the composition and material architecture. Moreover, porosity can be also induced at varied level as suggested by Bhat et al. [28] who induced different porosity level in carbon fiber reinforced epoxy resin resulting in different mechanical properties. Recently, this approaching is important for more extensive research on the light-weight materials with application in the space or automotive industry. Experimentally derived equations describe porous composite materials on the macroscopic level which make them independent on the pore size and nature. 


\section{Experimental}

\subsection{Materials}

The isocyanate pre-polymer (Unixin PU4223CS, Lear, s.r.o., Czech Republic, methylene-di-phenyl di-isocyanate, $6.9 \mathrm{wt} \%$ of $-\mathrm{NCO}$ groups, $\mathrm{M}_{\mathrm{n}}=690 \mathrm{~g} / \mathrm{mol}$ ) was used for the preparation of PUR matrix via curing with (i) distilled water, (ii) glycerol (Penta Chemicals, Czech Republic) and (iii) castor oil (Fichema, Czech Republic). Linseed oil (Fichema, Czech Republic) was used for plasticization of selected PUR cured with castor oil. Di-butyltin di-laureate (Lear, Czech Republic, DBTL) was used as catalyst.

The ground rubber recycled from car tyres (RPG Recycling s.r.o., Uherský Brod, Czech Republic), limestone, iron (Pkchemie, Czech Republic) and quartz (Millisil W12, Provodínské písky a.s., Provodín, Czech Republic) were used as filler. Ground rubber was supplied in 3 fractions with different particles size distribution $\left(R_{2}\right.$-the greatest, $R_{1}$-medium and $R_{0}$-the lowest). All fillers were composed of randomly-shaped particles. The shape of inorganic filler was defined by scanning electron microscope Tescan MIRA3 (Fig. 1). Particles size distribution of different filler was determined by laser analyser HELOS (H2568) \& RODOS and is depicted in Fig. 1. The particles size distribution of rubber fraction $R_{2}$ was determined by sieve analysis where the particles size $>800 \mu \mathrm{m}$ was determined (the diameter of more than $50 \%$ of particles greater than $2.5 \mathrm{~mm}$ ). Pycnometric density measurement was performed with following results: $1.18 \mathrm{~g} \mathrm{~cm}^{-3}$ (all rubber fractions), $2.65 \mathrm{~g} \mathrm{~cm}^{-3}$ (quartz), $2.68 \mathrm{~g} \mathrm{~cm}^{-3}$ (limestone) and $7.03 \mathrm{~g} \mathrm{~cm}^{-3}$ (iron).

\subsection{Preparation of samples}

PUR matrices with different concentration of PU4223 CS pre-polymer $(P)$ and curing agents were used for the preparation of PUR composites (Table 1). PUR prepolymer was cured by water (W), glycerol (G), castor oil (CO) or by combination of $\mathrm{G}$ and $\mathrm{CO}$. In the case of the PU4233 CS/CO combination, linseed oil (LO) was added as a plasticizer to prepare PUR matrix with different mechanical properties. Different inorganic fillers including $\mathrm{SiO}_{2}(\mathrm{Si}), \mathrm{CaCO}_{3}(\mathrm{Ca})$ and $\mathrm{Fe}(\mathrm{Fe})$ were particularly applied for the modification of mechanical properties and porosity of PUR matrices prepared with the same pre-polymer/curing agent ratio. Prepared matrices were filled with different volume fractions of ground rubber $\left(R_{0}, R_{1}, R_{2}\right)$ according to Table 2 . The porosity is neglected for all samples, e.g. with respect to the volume content of filler.

First, the pre-polymer, curing agent(s), catalyst and eventually plasticizer were intensively homogenized. Then the required mass of filler or fillers mixture (including inorganics and rubber) was added and carefully homogenized. Thus prepared mixture was loaded into molds $(120 \times 24 \times 12 \mathrm{~mm})$ covered with polyethylene foil for improved separation and the curing was performed under ambient conditions. Prepared specimens were weighted and their dimensions were measured.
Fig. 1 Particle size distributions and SEM images of filler particles

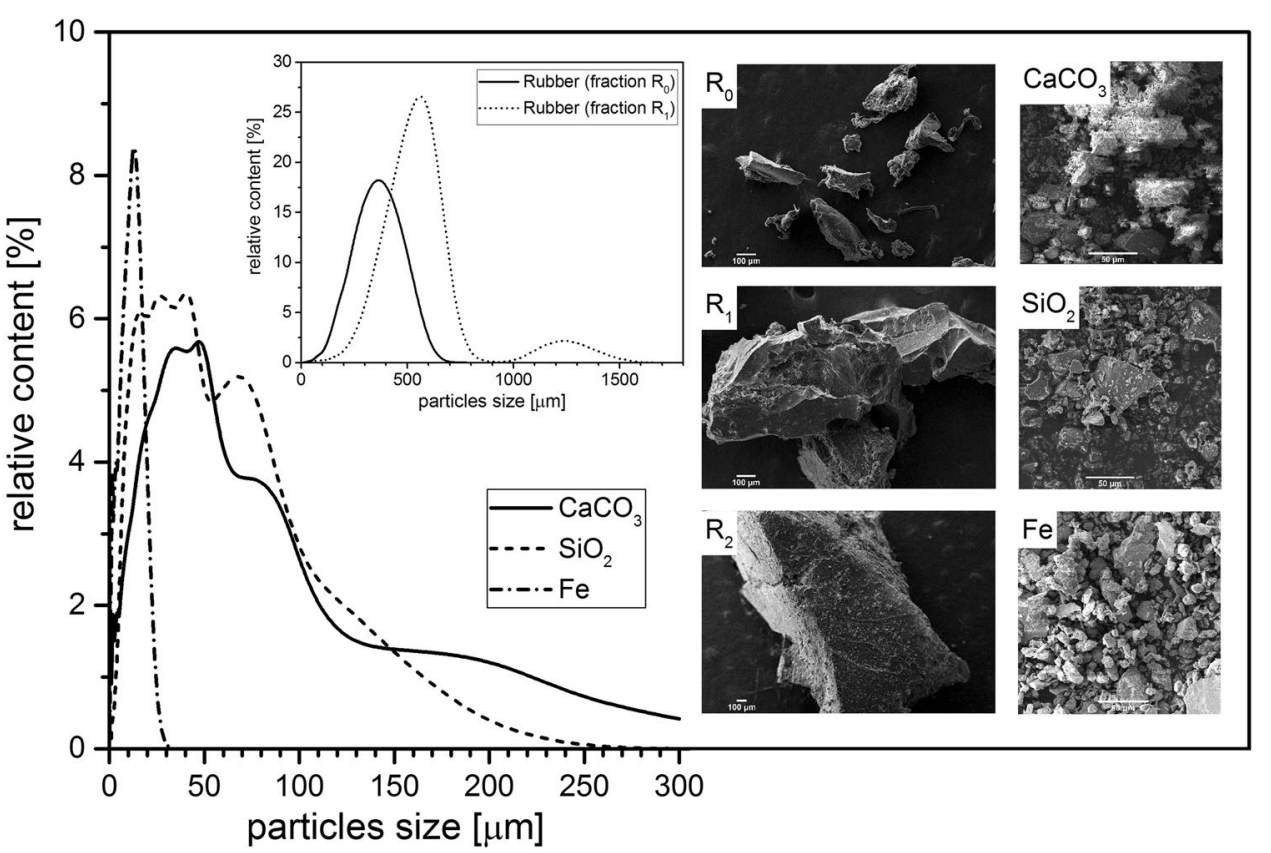

SN Applied Sciences A SPRINGER NATURE journa 
Table 1 Chemical composition of PUR matrices (P-PU4223 CS; curing agents: $\mathrm{W}-$ water, G-glycerol, CO-castor oil; plasticizer: LO_linseed oil; fillers included in matrices: $\mathrm{Si}-$ $\left.\mathrm{SiO}_{2}, \mathrm{Ca}-\mathrm{CaCO}_{3}, \mathrm{Fe}-\mathrm{Fe}\right)$

\begin{tabular}{llllll}
\hline Designation & $\begin{array}{l}\text { PU4223 CS } \\
\text { (vol\%) }\end{array}$ & Curing agent (vol\%) & Others (vol\%) & $\delta^{\mathrm{a}}(-)$ & DBTL $^{\mathrm{b}}$ (wt\%) \\
\hline $\mathrm{P}_{99}-\mathrm{W}_{1}$ & 99 & $1(\mathrm{~W})$ & - & $0.68^{\mathrm{c}}$ & 0.1 \\
$\mathrm{P}_{95}-\mathrm{G}_{5}$ & 95 & $5(\mathrm{G})$ & - & 1.22 & 0.03 \\
$\mathrm{P}_{80}-\mathrm{G}_{20}$ & 80 & $20(\mathrm{G})$ & - & 5.79 & 0.03 \\
$\mathrm{P}_{85}-\mathrm{G}_{5}-\mathrm{CO}_{10}$ & 85 & $5(\mathrm{G})+10(\mathrm{CO})$ & - & 1.55 & 0.03 \\
$\mathrm{P}_{65}-\mathrm{CO}_{35}$ & 65 & $35(\mathrm{CO})$ & - & 0.87 & 0.1 \\
$\mathrm{P}_{49}-\mathrm{CO}_{26}-\mathrm{LO}_{25}$ & 49 & $26(\mathrm{CO})$ & $25(\mathrm{LO})$ & 0.87 & 0.1 \\
$\mathrm{P}_{33}-\mathrm{CO}_{17}-\mathrm{Si}_{50}$ & 33 & $17(\mathrm{CO})$ & $50(\mathrm{Si})$ & 0.87 & 0.1 \\
$\mathrm{P}_{33}-\mathrm{CO}_{17}-\mathrm{Ca}_{50}$ & 33 & $17(\mathrm{CO})$ & $50(\mathrm{Ca})$ & 0.87 & 0.1 \\
$\mathrm{P}_{33}-\mathrm{CO}_{17}-\mathrm{Fe}_{50}$ & 33 & $17(\mathrm{CO})$ & $50(\mathrm{Fe})$ & 0.87 & 0.1 \\
$\mathrm{P}_{72}-\mathrm{G}_{18}-\mathrm{Ca}_{10}$ & 72 & $18(\mathrm{G})$ & $10(\mathrm{Ca})$ & 5.79 & 0.03 \\
\hline
\end{tabular}

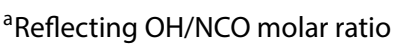

${ }^{\mathrm{b}}$ Based on the weight of PU $4223 \mathrm{CS}$

${ }^{\mathrm{C}}$ For this purpose $\mathrm{H}_{2} \mathrm{O}$ represents two $\mathrm{OH}$ groups
Table 2 Summary of prepared composites (differences in individual concentrations are $10 \mathrm{vol} \%)$

\begin{tabular}{llll}
\hline Matrix & \multicolumn{2}{l}{ Filler (vol\%) } \\
\cline { 2 - 4 } & $\mathrm{R}_{0}$ & $\mathrm{R}_{1}$ & $\mathrm{R}_{2}$ \\
\hline $\mathrm{P}_{99}-\mathrm{W}_{1}$ & $20-90$ & $20-90$ & $20-90$ \\
$\mathrm{P}_{95}-\mathrm{G}_{5}$ & $20-90$ & $20-90$ & $20-90$ \\
$\mathrm{P}_{80}-\mathrm{G}_{20}$ & $20-80$ & $20-90$ & $20-90$ \\
$\mathrm{P}_{85}-\mathrm{G}_{5}-\mathrm{CO}_{10}$ & $20-90$ & $20-90$ & $20-90$ \\
$\mathrm{P}_{65}-\mathrm{C}_{35}$ & $20-90$ & $20-90$ & $20-90$ \\
$\mathrm{P}_{49}-\mathrm{CO}_{26}-\mathrm{LO}_{25}$ & $20-90$ & $20-90$ & $20-90$ \\
$\mathrm{P}_{33}-\mathrm{CO}_{17}-\mathrm{Si}_{50}$ & $20-70$ & $20-70$ & $20-80$ \\
$\mathrm{P}_{33}-\mathrm{CO}_{17}-\mathrm{Ca}_{50}$ & $20-80$ & $20-80$ & $20-90$ \\
$\mathrm{P}_{33}-\mathrm{CO}_{17}-\mathrm{Fe}_{50}$ & $20-80$ & $20-80$ & $20-80$ \\
$\mathrm{P}_{72}-\mathrm{G}_{18}-\mathrm{Ca}_{10}$ & $20-80$ & $20-90$ & $20-90$ \\
\hline
\end{tabular}

\subsection{Characterization methods}

Pycnometer method was applied for the specification of the filler densities in acetone. This method was used also for $\mathrm{P}_{99}-\mathrm{W}_{1}$ matrix embodying high porosity. Different measurement procedure was used for the other non-filled PUR matrices having low value of closed porosity. Density of porous material was derived from weight $(8-18 \mathrm{~g})$ and volume of samples as a difference of ethanol amount added into a narrow-necked vessel in the presence/ absence of the sample. Each measurement was carried out three times.

Porosity was determined by confocal laser scanning microscopy (CLSM, Lext OLS 3000, Olympus) from the analysis of fracture area in optical mode. The porosity was evaluated from 10 scans. Thus obtained porosity was used to calculate the density of theoretically nonporous matrix from the density of real porous matrix.
Tensile properties were evaluated by universal static materials testing machine (ZWICK Z010 ROELL) under the strain rate $30 \mathrm{~mm} \mathrm{~min}^{-1}$. The main interest was focused on tensile modulus $(E)$, ultimate strength $\left(\sigma_{F \max }\right)$, ultimate strain $\left(\varepsilon_{\text {Fmax }}\right)$ and specific energy need for ultimate strength achievement $\left(A_{F \max }\right)$. Tensile modulus was determined from the linear part of tensile curve in the strain range $0.05-0.25 \%$ and $A_{F \max }$ was calculated as an integral area below the tensile curve according to Eq. (5):

$A_{F \max }=\sum\left(\varepsilon_{n}-\varepsilon_{n-1}\right) \cdot \frac{\sigma_{n}+\sigma_{n-1}}{2} ; n \in\left\langle 1 ; n_{F \max }\right\rangle$

where $\sigma_{n}, \varepsilon_{n}$ and $\sigma_{n-1}, \varepsilon_{n-1}$ express the stress and strain in two neighboring points lying on stress-strain curve. Index $n$ expresses the order of the point on the curve and $n_{F \max }$ is the highest point on tensile curve corresponding to $\sigma_{F \max }$. $A_{F \max }$ unit is derived from the unit of $\sigma_{F m a x}$ according to Eq. (6) because $\varepsilon_{\text {Fmax }}$ is dimensionless:

$\sigma_{F \max }=\left[\frac{N}{m^{2}}\right] ; N=\frac{J}{m} \rightarrow A_{F \max }=\left[\frac{\mathrm{J}}{\mathrm{m}^{3}}\right]$

\section{Results and discussion}

\subsection{General relationship between structure parameters and mechanical properties of filled composites}

The determination of mechanical properties of individual components of prepared composites is important for the evaluation of composites behaviour as well as structural parameters as mentioned above. Therefore the pure PUR matrices without GR were prepared in the 
Table 3 Mechanical properties (Young modulus $E$, ultimate strength $\sigma_{F \max }$ ultimate strain $\varepsilon_{\text {Fmax }}$ and specific energy need corresponding to ultimate strength achievement $\left.A_{F \max }\right)$, density of theoretical nonporous matrix $\rho_{t}$ and whole porosity $n_{m}$ of PUR matrices

\begin{tabular}{lllrrrc}
\hline Designation & $\mathrm{E}(\mathrm{MPa})$ & $\sigma_{\mathrm{Fmax}}(\mathrm{MPa})$ & $\varepsilon_{\mathrm{Fmax}}(\%)$ & \multicolumn{1}{c}{$\mathrm{A}_{\mathrm{Fmax}}\left(\mathrm{kJ} \cdot \mathrm{m}^{-3}\right)$} & $\rho_{\mathrm{t}}\left(\mathrm{g} \cdot \mathrm{cm}^{-3}\right)$ & $\mathrm{n}_{\mathrm{m}}(\%)$ \\
\hline $\mathrm{P}_{99}-\mathrm{W}_{1 \text { (more porous) }}$ & $1.4 \pm 0.3$ & $0.56 \pm 0.05$ & $94 \pm 9$ & $321 \pm 14$ & $1.10^{\mathrm{a}}$ & $57 \pm 7$ \\
$\mathrm{P}_{99}-\mathrm{W}_{1}$ (less porous) & $4.1 \pm 0.1$ & $2.7 \pm 0.3$ & $82 \pm 12$ & $1400 \pm 400$ & $1.10^{\mathrm{a}}$ & $16 \pm 2$ \\
$\mathrm{P}_{95}-\mathrm{G}_{5}$ & $13 \pm 2$ & $4.7 \pm 0.1$ & $140 \pm 40$ & $4100 \pm 700$ & $1.12^{\mathrm{b}}$ & $9.5 \pm 0.7$ \\
$\mathrm{P}_{80}-\mathrm{G}_{20}$ & $4.8 \pm 0.3$ & $1.75 \pm 0.08$ & $340 \pm 20$ & $3700 \pm 300$ & $1.15^{\mathrm{b}}$ & $10 \pm 1$ \\
$\mathrm{P}_{85}-\mathrm{G}_{5}-\mathrm{CO}_{10}$ & $2.3 \pm 0.3$ & $1.24 \pm 0.04$ & $100 \pm 4$ & $700 \pm 50$ & $1.05^{\mathrm{b}}$ & $2 \pm 2$ \\
$\mathrm{P}_{65}-\mathrm{CO}_{35}$ & $1.6 \pm 0.4$ & $0.42 \pm 0.03$ & $39 \pm 4$ & $69 \pm 6$ & $1.04^{\mathrm{b}}$ & $4 \pm 1$ \\
$\mathrm{P}_{49}-\mathrm{CO}_{26}-\mathrm{LO}_{25}$ & $1.1 \pm 0.03$ & $0.4 \pm 0.03$ & $68 \pm 8$ & $90 \pm 8$ & $1.03^{\mathrm{b}}$ & $1 \pm 2$ \\
$\mathrm{P}_{33}-\mathrm{CO}_{17}-\mathrm{Si}_{50}$ & $9 \pm 1$ & $2.2 \pm 0.3$ & $22 \pm 1$ & $210 \pm 40$ & $1.85^{\mathrm{c}}$ & $16 \pm 1$ \\
$\mathrm{P}_{33}-\mathrm{CO}_{17}-\mathrm{Ca}_{50}$ & $4.9 \pm 0.5$ & $0.7 \pm 0.04$ & $20 \pm 1$ & $69 \pm 9$ & $1.86^{\mathrm{c}}$ & $32 \pm 2$ \\
$\mathrm{P}_{33}-\mathrm{CO}_{17}-\mathrm{Fe}_{50}$ & $9.1 \pm 0.6$ & $1.09 \pm 0.09$ & $13 \pm 1$ & $70 \pm 10$ & $4.04^{\mathrm{c}}$ & $22.6 \pm 0.5$ \\
$\mathrm{P}_{72}-\mathrm{G}_{18}-\mathrm{Ca}_{10}$ & $7.4 \pm 0.8$ & $1.93 \pm 0.06$ & $260 \pm 30$ & $3700 \pm 300$ & $1.30^{\mathrm{c}}$ & $16.3 \pm 0.6$ \\
\hline
\end{tabular}

${ }^{\text {a }}$ Measured by pycnometer method

${ }^{b}$ Obtained from knowledge about volume, mass and porosity

${ }^{c}$ Calculated via simple mixing equation
Fig. 2 CLSM images of $\mathrm{P}_{33}$ $\mathrm{CO}_{17}-\mathrm{Ca}_{50}$ composite filled with different fractions of rubber: a 20 vol $\% \mathrm{R}_{2} ; \mathbf{b} 20$ vol $\%$ of $R_{0}, \mathbf{c} 50$ vol\% of $R_{2}$ and $\mathbf{d} 50$ vol\% of $R_{0}$
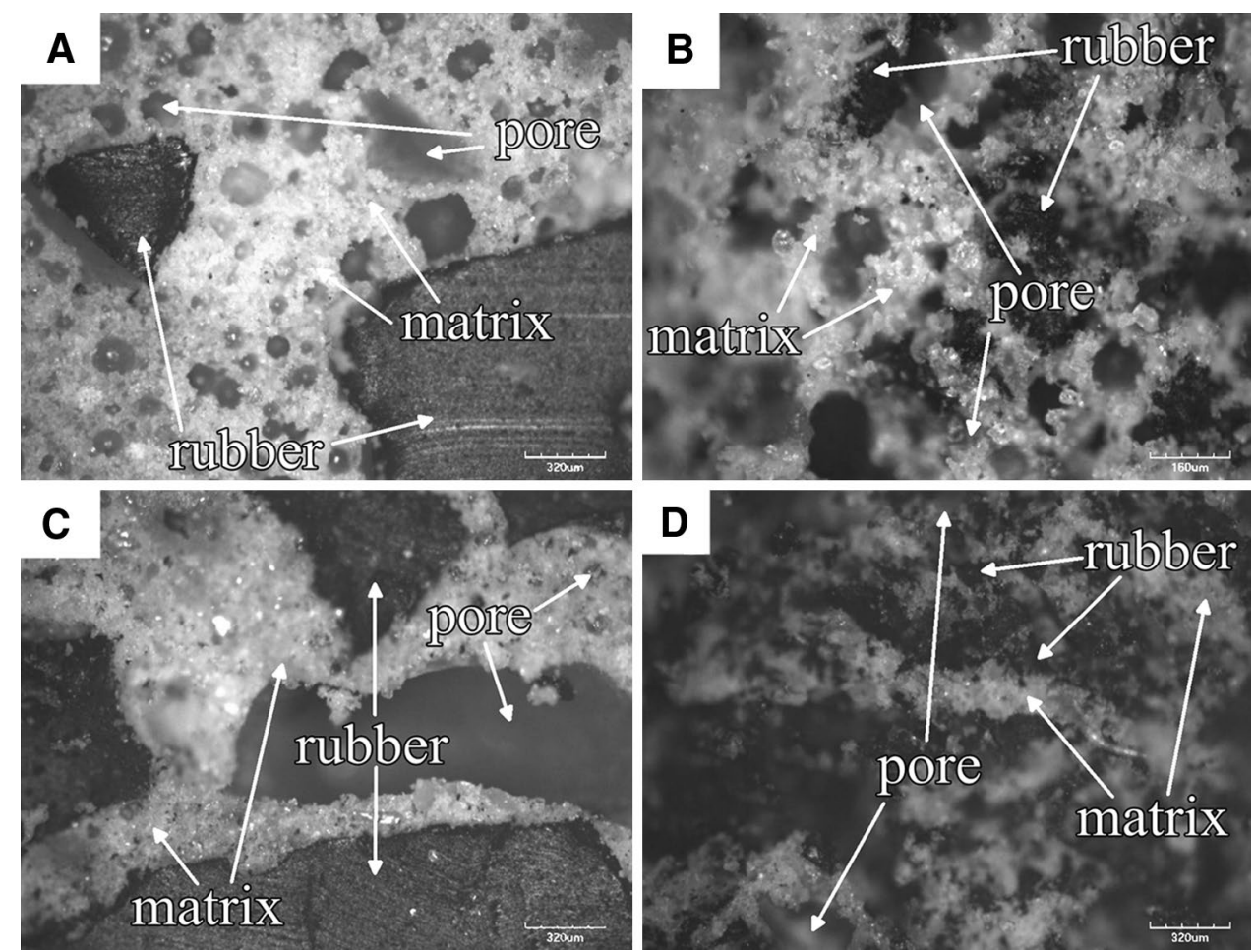

first phase whereas their composition was designed in order to achieve different mechanical properties and different bulk porosity. Values of mechanical properties, porosity and density of PUR matrices are listed in Table 3. It is evident that the addition of filler into the PUR matrix raises elastic modulus $E$ depending on the nature of filler and particles size distribution. Moreover, porosity increases due to poor interfacial adhesion between matrix and filler. Narrow particles size distribution of $\mathrm{Fe}\left(\mathrm{P}_{33}-\mathrm{CO}_{17}-\mathrm{Fe}_{50}\right)$ results in the relatively high $E$ and low $\varepsilon_{\mathrm{Fmax}}$ due to poor assembling of Fe particles in the intermolecular space and limitation of chain mobility. As mentioned in the Introduction, the porosity affects mechanical properties as evident for $\mathrm{P}_{99}-\mathrm{W}_{1}$ samples with different porosity content (Table 1). The addition of castor oil (CO) as a curing agent results in more elastic matrix as reflected by the decrease of $E$ due to greater free volume between PUR chains.

Since PUR matrix can be generally prepared in various form such as foam, porous or nonporous bulk material, the 
structure of thus prepared porous composites corresponds with the shape of filler and matrix properties (e.g., elastic modulus $E$, strain $\varepsilon$, porosity, etc.) and strongly affects mechanical properties. As shown in Fig. 2, the filler affects the material porosity and can act as a barrier for degassing. Theoretically, if the concentration of filler particles is high enough, the porosity would decrease due to low content of vacations and low content of matrix. Nevertheless, in this case the porosity usually increases due to inability of matrix to fill the space between filler particles. Proposed effect is demonstrated for $\mathrm{P}_{33}-\mathrm{CO}_{17}-\mathrm{Ca}_{50}$ matrix filled with $\mathrm{R}_{0}$ and $\mathrm{R}_{2}$ rubber particles which are surrounded by vacations (Fig. 2).

Selected mechanical properties in Table 3 were derived from tensile testing, specifically tensile modulus $(E)$, ultimate strength $\left(\sigma_{\mathrm{Fmax}}\right)$, ultimate strain $\left(\varepsilon_{\mathrm{Fmax}}\right)$ and energy need corresponding to ultimate strength achievement $\left(A_{\text {Fmax }}\right)$. Mechanical properties-PUR composition combination can be fitted by simple equation in the form of cubic power function:

$z_{c}=z_{m} \cdot n_{p}^{b} \cdot\left(1-v_{f}\right)^{c}$ where $z$ is the selected mechanical property, $z_{c}$ and $z_{m}$ represent the same property for composite and nonporous matrix, respectively. Coefficients $b$ and $c$ were derived from the fitting measured data according to Eq. (7) regarding

Table 4 Mechanical properties of theoretically nonporous matrices obtained by fitting of composites mechanical properties according to the Eq. (7)

\begin{tabular}{lrlll}
\hline Matrix & $\mathrm{E}(\mathrm{MPa})$ & $\sigma_{\mathrm{Fmax}}(\mathrm{MPa})$ & $\varepsilon_{\mathrm{Fmax}}(-)$ & $\mathrm{A}_{\mathrm{Fmax}}\left(\mathrm{kJ} \mathrm{m}^{-3}\right)$ \\
\hline $\mathrm{P}_{99}-\mathrm{W}_{1}$ & 5.30 & 3.38 & 1.25 & 2871 \\
$\mathrm{P}_{95}-\mathrm{G}_{5}$ & 19.38 & 5.17 & 1.19 & 3377 \\
$\mathrm{P}_{80}-\mathrm{G}_{20}$ & 5.17 & 1.49 & 5.72 & 6920 \\
$\mathrm{P}_{85}-\mathrm{G}_{5}-\mathrm{CO}_{10}$ & 1.98 & 1.02 & 1.62 & 1004 \\
$\mathrm{P}_{65}-\mathrm{CO}_{35}$ & 2.02 & 0.42 & 0.38 & 111 \\
$\mathrm{P}_{49}-\mathrm{CO}_{26}-\mathrm{LO}_{25}$ & 1.19 & 0.29 & 0.50 & 83 \\
$\mathrm{P}_{33}-\mathrm{CO}_{17}-\mathrm{Si}_{50}$ & 14.09 & 4.50 & 0.22 & 435 \\
$\mathrm{P}_{33}-\mathrm{CO}_{17}-\mathrm{Ca}_{50}$ & 13.46 & 1.28 & 0.19 & 167 \\
$\mathrm{P}_{33}-\mathrm{CO}_{17}-\mathrm{Fe}_{50}$ & 18.53 & 1.70 & 0.14 & 153 \\
$\mathrm{P}_{72}-\mathrm{G}_{18}-\mathrm{Ca}_{10}$ & 6.48 & 1.62 & 3.41 & 5320 \\
\hline
\end{tabular}
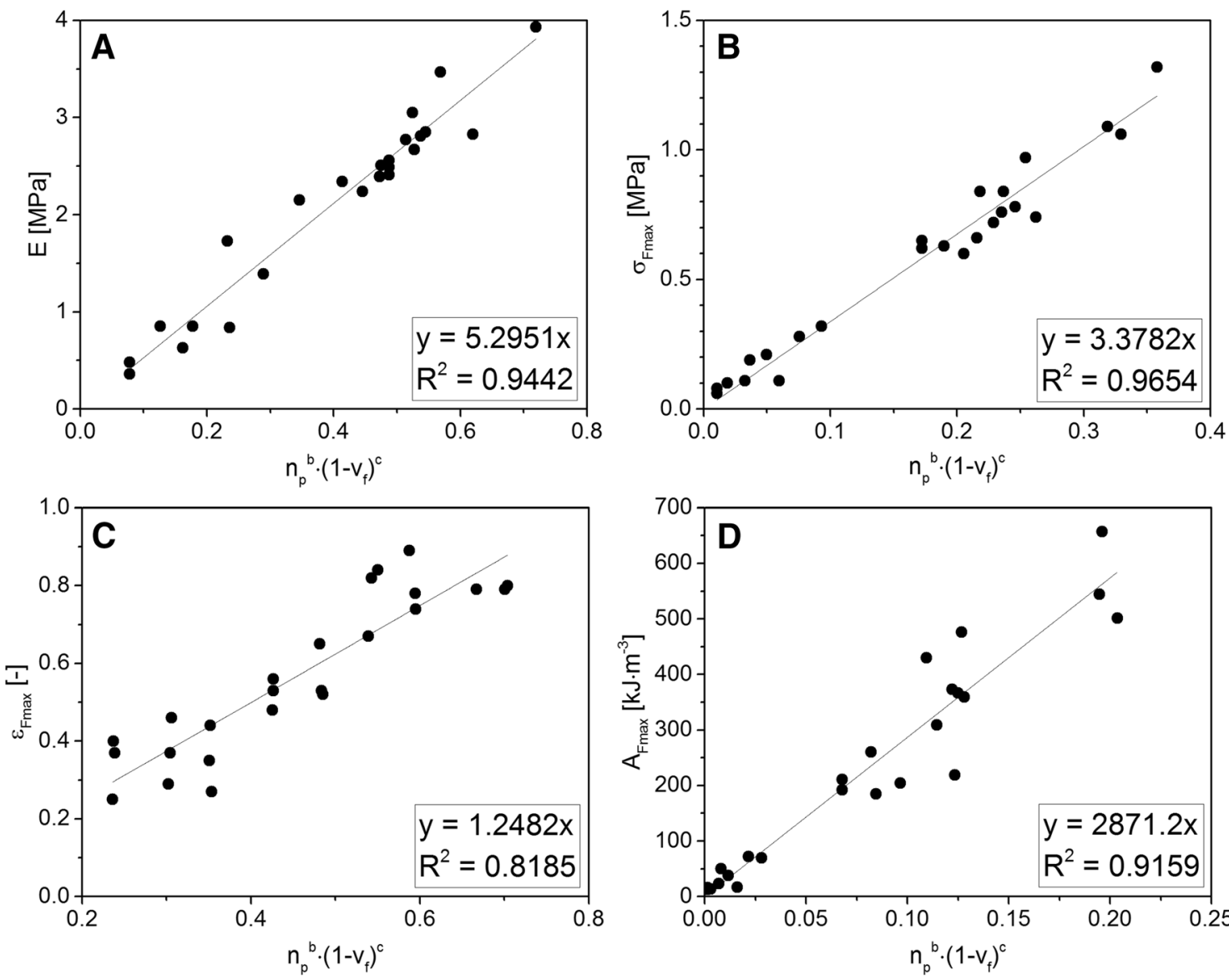

Fig. 3 Linear fitting of plot between properties of porous composites containing $\mathrm{P}_{99}-\mathrm{W}_{1}$ matrix filled by different fractions of rubber includ$\operatorname{ing} E(\mathbf{a}), \sigma_{F \max }(\mathbf{b}), \varepsilon_{F \max }(\mathbf{c})$ and $A_{F \max }(\mathbf{d})$ and expression $\left(n_{p}^{b}-\left(1-v_{f}\right)^{c}\right)$-data fitted according to power Eq. (7) 
the highest coefficient $R^{2}$ for linear function derived from the plot between $z_{c}$ and $n_{p}{ }^{b} \cdot\left(1-v_{f}\right)^{c}$ (Fig. 3). All slopes $\left(z_{m}\right)$ obtained by Eq. (7) fitting are shown in Table 4.

Values of $n_{p}$ and $\left(1-v_{f}\right)$ of unfilled nonporous matrix equal to 1 . Therefore, the axis $x$ value for nonporous matrix equals to 1 . Then the slope of linearized function should be equal to the value of selected property for pure nonporous matrix. However, the Eq. (7) can be modified also for porous matrix and nonporous composite as summarized in Table 5.
The Eq. (7) represents fitting of measured data but does not describe material behavior. Therefore, exponents $b$ and $c$ were substituted by functions derived from logarithmic fitting (Figs. 4 and 5) and included in Eqs. (17)-(18) and (20)-(21) providing connection with individual mechanical properties where subscripts $m$ and $c$ represent mechanical properties of nonporous matrix and composite, respectively. Exponents $d, e$ and $f, g$ were extracted from logarithmic fitting in Figs. 4 and 5 , respectively. Equation (7) is then changed into several following relationships including (13)-(14) and (16)-(17):

Table 5 Modification of Eq. (7) for porous/nonporous matrix/

\begin{tabular}{llllll}
\hline Material & Relationship & \multicolumn{2}{l}{ Value ranges of } & Equations \\
\cline { 3 - 5 } & & $\mathrm{n}_{\mathrm{p}}$ & $1-\mathrm{v}_{\mathrm{f}}$ & $\mathrm{n}_{\mathrm{p}}^{\mathrm{b}} \cdot\left(1-\mathrm{v}_{\mathrm{f}}\right)^{c}$ & \\
\hline Porous composite & $z_{c}=z_{m} \cdot n_{p}^{b} \cdot\left(1-v_{f}\right)^{c}$ & $(0 ; 1)$ & $(0 ; 1)$ & $(0 ; \infty)$ & $(8)$ \\
Nonporous composite & $z_{c}=z_{m} \cdot\left(1-v_{f}\right)^{c}$ & $\langle 1\rangle$ & $(0 ; 1)$ & $(0 ; \infty)$ & $(9)$ \\
Porous matrix & $z_{c}=z_{m} \cdot n_{p}^{b}$ & $(0 ; 1)$ & $\langle 1\rangle$ & $(0 ; \infty)$ & $(10)$ \\
Nonporous matrix & $z_{c}=z_{m}$ & $\langle 1\rangle$ & $\langle 1\rangle$ & $\langle 1\rangle$ & $(11)$ \\
Powder filler & $z_{c}=0$ & $\langle 0\rangle$ & $\langle 0 ; 1)$ & $\langle 0\rangle$ & $(12)$ \\
\hline
\end{tabular}
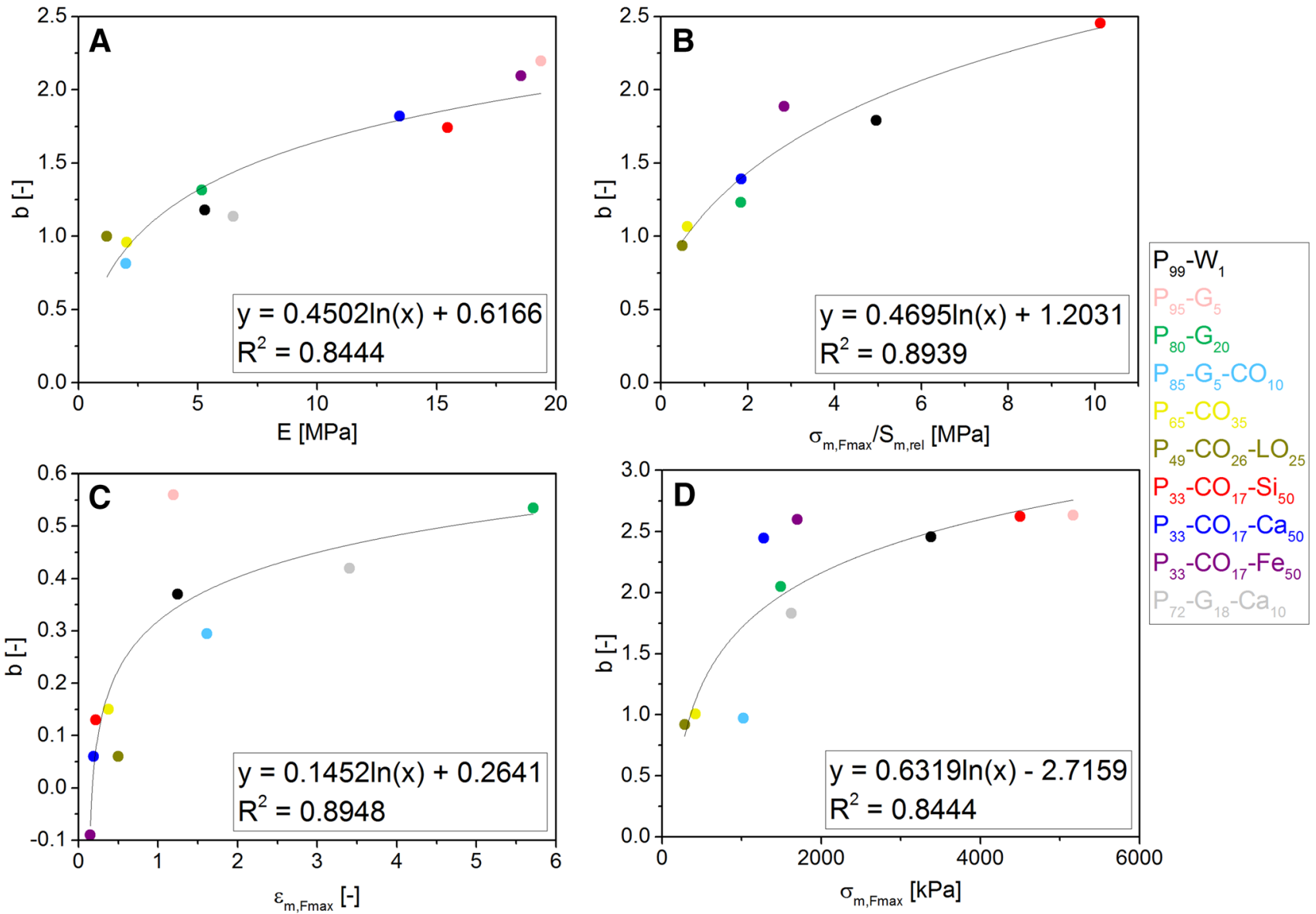

Fig. 4 Logarithmic fitting of plots between parameter $b$ and $E_{m}(\mathbf{a}), \sigma_{m, F m a x} / S_{m, r e l}(\mathbf{b}), \varepsilon_{m, F \max }(\mathbf{c})$ and $\sigma_{m, F \max }(\mathbf{d}): y=d+e \cdot \ln (x)$ 

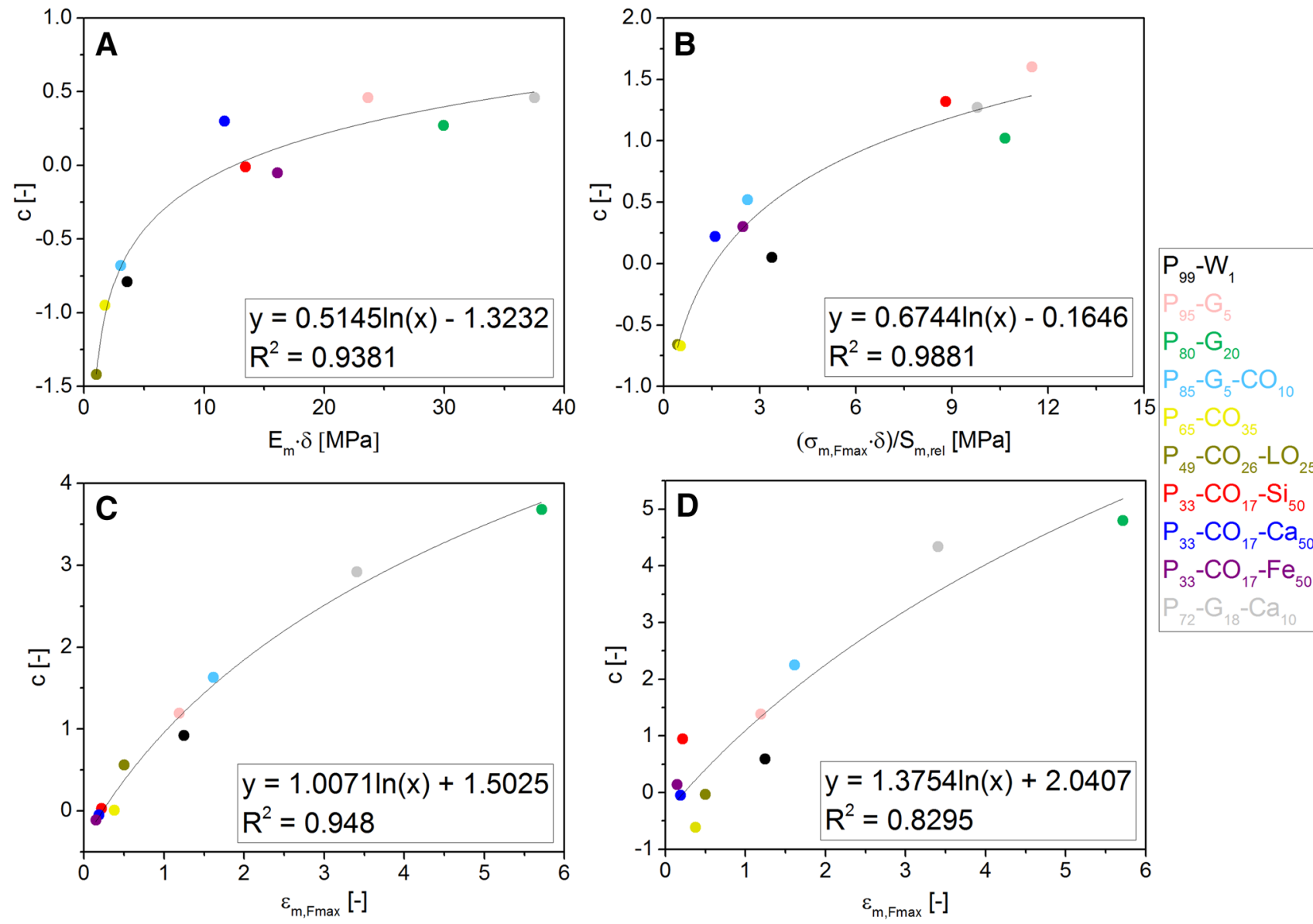

$\mathrm{P}_{33}-\mathrm{CO}_{17}-\mathrm{Si}_{50}$ $\mathrm{P}_{33}-\mathrm{CO}_{17}-\mathrm{Ca}_{50}$ $\mathrm{P}_{33}-\mathrm{CO}_{17}-\mathrm{Fe}_{50}$ $P_{72}-G_{18}-\mathrm{Ca}_{10}$

Fig. 5 Logarithmic fitting of plots between parameter $c$ and $E_{m} \cdot \delta(\mathbf{a}), \sigma_{m, F m a} \cdot \delta / S_{m, r e l}(\mathbf{b}), \varepsilon_{m, F m a x}(\mathbf{c})$ and $\varepsilon_{m, F m a x}(\mathbf{d}): y=f+g \cdot \ln (x)$

$E_{c}=E_{m} \cdot n_{p}^{d+e \cdot \ln E m} \cdot\left(1-v_{f}\right)^{f+g \cdot \ln \left(E_{m} \cdot \delta\right)}$

where $\delta$ is $\mathrm{OH} / \mathrm{NCO}$ molar ratio in matrix before curing and should be sufficient for relative matrix polarity expression. The $\delta$ value is not different for polymeric and composite matrix based on the same PUR. The reason could be the encapsulating of inorganic particles in the basic PUR matrix. Polarity of matrix should serve as the adhesion coefficient since the chemical origin of filler was the same (only rubber). It has to be mentioned that some PUR matrices were cured with the excess of $-\mathrm{OH}$ groups resulting in the excess of unreacted functional groups. The ratio of reactive groups was used in this role with the assumption that all PUR matrices exhibit approximately the same polarity when the concentration of $-\mathrm{OH}$ groups is neglected:

$\sigma_{c, F \max }=\sigma_{m, F \max } \cdot n_{p}^{d+e \cdot \ln \left(\frac{\sigma_{m, F \max }}{s_{m, r e l}}\right)} \cdot\left(1-v_{f}\right)^{f+g \cdot \ln \left(\frac{\sigma_{m, F \max \delta \delta}}{s_{m, r e l}}\right)}$ where $S_{m, r e l}$ is the integral area (values in the range $0-1$ ) lying under the tensile curve of nonporous matrix and the relationship for its calculation (Eq. (15)) was derived from the basic relationship given by Eq. (6):

$$
\begin{aligned}
S_{m, r e l} & =\frac{A_{m, F \max }}{\sigma_{m, F \max } \cdot \varepsilon_{m, F \max }} \\
& =\sum \frac{\varepsilon_{n}-\varepsilon_{n-1}}{\varepsilon_{m, F \max }} \cdot \frac{\sigma_{n}+\sigma_{n-1}}{2 \cdot \sigma_{m, F \max }} ; n \in\left\langle 1 ; n_{F \max }\right\rangle
\end{aligned}
$$

Values of mechanical properties in Eq. (15) were derived from fitted data in Table 4, since it was not possible to prepare absolutely nonporous matrix. The area below tensile curve of nonporous matrix was used for improving the fitting of exponent $b$ and $c$ in the case of $\sigma_{c, \text { Fmax }}$ calculation (Eq. (14). This is the only difference in relationships describing $E$ and $\sigma_{F \max }$ which could be caused by the same $S_{m \text {,rel }}$ value for all $E$ measurements. The constant $S_{m, r e l}$ value (approx. 0.5) is caused by linearity of the initial stage of tensile curve which is used for the determination of $E$. Therefore, the $S_{m, r e l}$ was excluded from the Eq. (13). 
Remaining relationships are dedicated to ultimate strain and specific energy required for ultimate strength achievement:

$\varepsilon_{c, F \max }=\varepsilon_{m, F \max } \cdot n_{p}^{d+e \cdot \ln \varepsilon m, F \max } \cdot\left(1-v_{f}\right)^{f+g \cdot \ln \varepsilon m, F \max }$

$A_{c, F \max }=A_{m, F \max } \cdot n_{p}^{d+e \cdot \ln \sigma m, F \max } \cdot\left(1-v_{f}\right)^{f+g \cdot \ln \varepsilon m, F \max }$

\subsection{Advanced relationships between structure parameters and mechanical properties of filled composites}

General discrete relationships do not distinguish the origin of porosity, specifically whether the porosity occurs during the preparation of PUR matrix or after the addition of filler. Equations (13)-(17) can be modified by substituting the data for nonporous matrices (slopes of data fitting according Eq. (13), see also Fig. 3 and Table 4) by measured data of real porous matrices $\left(E_{m n^{\prime}}, \sigma_{m n, F m a x}, \varepsilon_{m n, F \max } A_{m n, F m a x}\right.$ and $S_{m n, \text { rel }}$ in Table 3). Instead of $S_{m, \text { rel }}$ values, $S_{m n, \text { rel }}$ represents porous matrices (calculated by Eq. (15) from data in Table 3). The interspace filling of composite $\left(n_{\mathrm{p}}\right)$ can be divided by $\left(1-n_{m}\right)$, where $\left(1-n_{m}\right)$ equals to $n_{p}$ for unfilled matrix (see $n_{\mathrm{m}}$ values in Table 3). The $d, e, f$ and $g$ values were taken from Eqs. (13)-(14) and (16)-(17) (accurate values shown in the Figs. 4 and 5 in relations). Calculation of $E_{C^{\prime}} \sigma_{c, F \max } \varepsilon_{c, F \max }$ and $A_{c, F \max }$ (composites based on porous matrix) is then given by Eq. (18)-(21). Modified equations were used to recalculate the data that had been measured

Table 6 Accordance results between real data and data calculated by Eqs. (18-21)

\begin{tabular}{lllll}
\hline PUR matrix & $\mathrm{E}$ & $\sigma_{\text {Fmax }}$ & $\varepsilon_{\text {Fmax }}$ & $\mathrm{A}_{\text {Fmax }}{ }^{\mathrm{a}}$ \\
\hline $\mathrm{P}_{99}-\mathrm{W}_{1}$ (more porous) & 1.10 & 1.12 & 0.90 & 1.80 \\
$\mathrm{P}_{99}-\mathrm{W}_{1}$ (less porous) & 0.98 & 0.91 & 1.12 & 1.18 \\
$\mathrm{P}_{95}-\mathrm{G}_{5}$ & 0.96 & 0.91 & 0.72 & 0.87 \\
$\mathrm{P}_{80}-\mathrm{G}_{20}$ & 0.95 & 0.85 & 1.06 & 0.84 \\
$\mathrm{P}_{85}-\mathrm{G}_{5}-\mathrm{CO}_{10}$ & 0.91 & 0.90 & 1.09 & 0.91 \\
$\mathrm{P}_{65}-\mathrm{CO}_{35}$ & 1.08 & 1.02 & 1.07 & 0.97 \\
$\mathrm{P}_{49}-\mathrm{CO}_{26}-\mathrm{LO}_{25}$ & 1.08 & 0.78 & 0.80 & 0.55 \\
$\mathrm{P}_{33}-\mathrm{CO}_{17}-\mathrm{Si}_{50}$ & 0.99 & 1.00 & 0.98 & 0.42 \\
$\mathrm{P}_{33}-\mathrm{CO}_{17}-\mathrm{Ca}_{50}$ & 0.98 & 0.96 & 0.99 & 0.41 \\
$\mathrm{P}_{33}-\mathrm{CO}_{17}-\mathrm{Fe}_{50}$ & 1.05 & 0.89 & 1.28 & 0.35 \\
$\mathrm{P}_{72}-\mathrm{G}_{18}-\mathrm{Ca}_{10}$ & 0.79 & 0.85 & 0.89 & 0.66 \\
\hline
\end{tabular}

Slopes values belong to linear functions going throw beginning and containing dependences of real data on those calculated. Each value serves for one property and composites based on one matrix. Total accordance is equal to 1

a Low accordance usually in cases of low $A_{\text {Fmax }}$ values of used matrices for improved accordance between measured and calculated data. Then the linear dependences of measured data on the recalculated were created separately for each pair of composite samples based on one PUR matrix and chosen property. Obtained slopes served as the extent of accordance between recalculated and measured data. Thus obtained values of slopes are shown in Table 6 for all measured data.

$$
\begin{gathered}
E_{c}=E_{m n} \cdot\left(\frac{n_{p}}{1-n_{m}}\right)^{d+e \cdot \ln E m n} \cdot\left(1-v_{f}\right)^{f+g \cdot \ln \left(E_{m n} \cdot \delta\right)} \\
\sigma_{c, F \max }=\sigma_{m n, F \max } \cdot\left(\frac{n_{p}}{1-n_{m}}\right)^{d+e \cdot \ln \left(\frac{\sigma_{m n, F \max }}{s_{m n, r e l}}\right)} \cdot \\
\left(1-v_{f}\right)^{f+g \cdot \ln \left(\frac{\sigma_{m n, F \max \delta}}{s_{m n, r e l}}\right)}
\end{gathered}
$$

$\varepsilon_{c, F \max }=\varepsilon_{m n, F \max } \cdot\left(\frac{n_{p}}{1-n_{m}}\right)^{d+e \cdot \ln \varepsilon m n, F \max } \cdot\left(1-v_{f}\right)^{f+g \cdot \ln \varepsilon m n, F \max }$

$A_{c, F \max }=A_{m n, F \max } \cdot\left(\frac{n_{p}}{1-n_{m}}\right)^{d+e \cdot \ln \sigma m n, F \max } \cdot\left(1-v_{f}\right)^{f+g \cdot \ln \varepsilon m n, F \max }$

The classification of porosity origin also assumes different values of $d$ and $e$ parameters and then different $b$ parameter for different fillers. General parameter $z_{m n}$ in the Eq. (18) (i.e., $\left.E_{m n}\right)$ also includes porosity of matrix and exponent $b$ including parameters $d$ and $e$ with different values than those for $z_{m}$ from Eq. (13) (i.e., $E_{m}$ ). Values of these parameters should be universal for individual mechanical properties of all porous materials that are homogeneous on macroscopic scale according to Eqs. (22)-(25). When different values of $d$ and $e$ are assumed for different cause of porosity, they can be assumed to be different also for different filler. However, only rubber as a filler was used in this study, this assumption will be under interest in the future work.

$E_{m n}=E_{m} \cdot\left(1-n_{m}\right)^{d+e \cdot \ln E m}$

$\sigma_{m n, F \max }=\sigma_{m, F \max } \cdot\left(1-n_{m}\right)^{d+e \cdot \ln \left(\frac{\sigma_{m, F \max }}{s_{m, r e l}}\right)}$

$\varepsilon_{m n, F \max }=\varepsilon_{m, F \max } \cdot\left(1-n_{m}\right)^{d+e \cdot \ln \varepsilon m, F \max }$

$A_{m n, F \max }=A_{m, F \max } \cdot\left(1-n_{m}\right)^{d+e \cdot \ln \sigma m, F \max }$

The evaluation of $d$ and $e$ parameters (valid for separate properties of porous unfilled materials, that are homogeneous on macroscopic level and the filler can be 
included in matrix) should be the next step. However, it is impossible to fit the data for porous matrices as well as for porous composites due to only one value of porosity for each matrix (porosity was a property of matrix). Only $\mathrm{P}_{99}-\mathrm{W}_{1}$ matrix was prepared in two types with different porosity caused by water and affected by (un)excision of bubbles arising from the surface during curing. This lack of experimental data required a change of approach according to Eq. (26) which generalizes Eqs. (22)-(25):

$z_{m n}=z_{m} \cdot\left(1-n_{m}\right)^{b}$

In Eq. (26) (comparable with Eqs. (1) and (2)), $z_{m}$ is only one unknown variable while $z_{m n}$ and $n_{m}$ are measurable. Individual mechanical properties for nonporous matrix $\left(z_{m}\right)$ were derived from data fitting according to Eqs. (13)-(17) valid for composites. Then the exponent $b$ can be expressed from Eq. (26) as the last unknown variable. Obtained $b$ values have been plotted against the $z_{m}$ values (Fig. 6) in similar way as shown in Fig. 4 to obtain the general $d$ and $e$ values for Eqs. (22)-(25). Except of structural parameters, humidity of filler could affect the data scattering. Specifically, isocyanate groups of pre-polymer are highly reactive towards humidity and thus the structure and mechanical properties of PUR composites could be affected by humidity of added filler used without drying. Accordingly, $z_{m}$ values of porous composites derived from the logarithmic fitting of porous composites (Fig. 3, Table 4) do not fit absolutely with measured $z_{m n}$ values for porous PUR matrix without the influence of filler addition.

\section{Conclusions}

This study is focused on the description of the mechanical behavior of porous PUR composites filled with rubber filler. Proposed relationships are dedicated to tensile modulus $(\mathrm{E})$, ultimate strength $\left(\sigma_{F \max }\right)$ and strain $\left(\varepsilon_{F \max }\right)$ and specific energy need $\left(A_{F \max }\right)$. Derivation of the relationships for porous filled composite was performed in two steps. First, exponential parameters were experimentally determined from data fitting using structural parameters called interspace filling and interspace volume and looking for exponents suitable for the best data fitting in discrete situations (the same property, the same composition beyond the rates of components). The second step included an effort to describe a meaning of powers obtained in the first step. It means the fitting of powers by logarithmic functions. Obtained relationships do not generally describe the role of filler in porous composite, since only the ground rubber was used as the filler for all composites. Accordingly, the use of different types of filler could lead to description of $d, e, f$ and $g$ members placed in exponent dependencies. However, proposed relationships enable probably an addition of infinite amount of filler types but they do not describe the influence of different types of filler absolutely. The reason is the addition of only rubbery fillers into PUR matrices. In future works it is necessary to find exact meaning of all members in structure-properties relationships for different systems. Suggested relations seem to be independent on the type of porosity (open and enclose pores, different pore size and distribution, etc.).
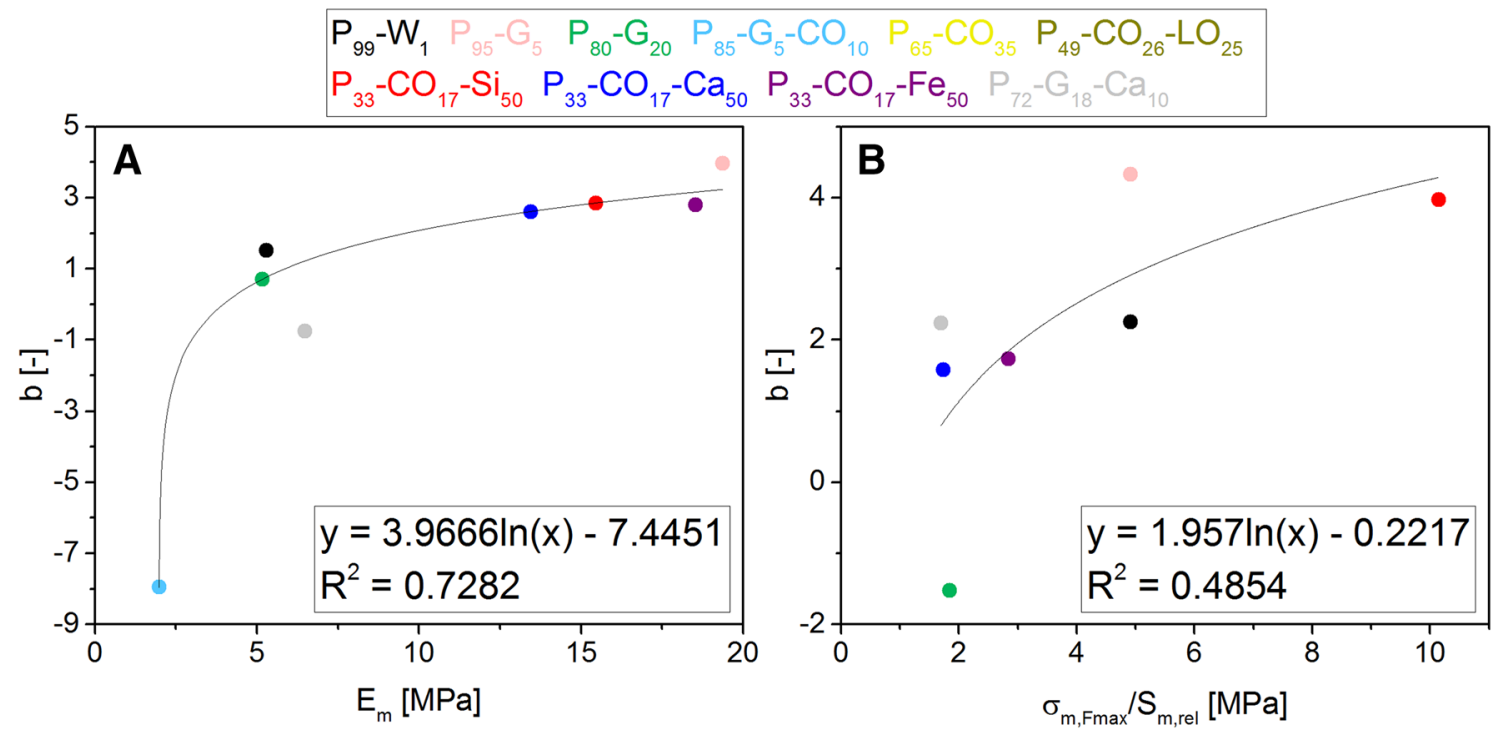

Fig. 6 Dependences of parameter $b$ from Eq. (22) on $E_{m}$ (a) and parameter $b$ from Eq. (23) on $\sigma_{m, F m a x} / S_{m, \text { rel }}$ (b). In the plots, there are shown only points except outliers 
Acknowledgements This was supported by the project CEITEC 2020 (LQ1601) with financial support from the Ministry of Education, Youth and Sports of the Czech Republic under the National Sustainability Programme II and by the project of Brno University of Technology (FCH-S-19-6100).

\section{Compliance with ethical standards}

Conflict of interest On behalf of all authors, the corresponding author states that there is no conflict of interest.

\section{Appendix}

\section{Advanced relationship between structure parameters and mechanical properties of filled composites: $\mathbf{n}$-component system}

According to Eqs. (18)-(21) and their extensions represented by Eqs. (22)-(25), each mentioned property of porous composite can be determined with respect to the origin of porosity. Creation of proposed relationships is the key to the complex relationships, which could determine mechanical properties of $\mathrm{n}$-component porous composite. The Eqs. (18) and (22) can be accompanied with this assumption resulting in Eq. (27). Equation (28) serves as its specification:

$E_{2 n}=E_{1 n} \cdot\left(\frac{n_{p 2}}{1-n_{1}}\right)^{d_{2}+e_{2} \cdot \ln E_{1 n}} \cdot\left(1-v_{f 2}\right)^{f_{2}+g_{2} \cdot \ln \left(E_{1 n} \cdot \delta\right)}$

where

$E_{1 n}=E_{1} \cdot\left(1-n_{1}\right)^{d_{1}+e_{1} \cdot \ln E_{1}}$

In the Eqs. (27) and (28), there is a lot of subscripts representing amount of phases in $\mathrm{n}$-component system ( 1 = matrix, 2 = two-component composite, $n=$ for $n$-component composite). If the number is added by letter $n$, the member value is valid for porous system. Also combination $n n$ is possible (for $\mathrm{n}$-component porous system). The members including porosity and interspace filling do not use subscript $n$ in case of porosity occurrence, because porosity occurrence is directly determined by their values.

For $\mathrm{n}$-component composite, the Eq. (27) turns into Eq. (29) valid for $E_{\mathrm{nn}}$ :

$E_{n n}=E_{n-1, n} \cdot\left(\frac{n_{p n}}{1-n_{n-1}}\right)^{d_{n}+e_{n} \cdot \ln E_{n-1, n}} \cdot\left(1-v_{f n}\right)^{f_{n}+g_{n} \cdot \ln \left(E_{n-1, n} \cdot \delta\right)}$

The same type of relationship can be obtained for other properties:

$$
\begin{aligned}
\sigma_{n n, F \max }= & \sigma_{n-1, n, F \max } \cdot\left(\frac{n_{p n}}{1-n_{n-1}}\right)^{d_{n}+e_{n} \cdot \ln \sigma_{n-1, n, F \max }} . \\
& \left(1-v_{f n}\right)^{f_{n}+g_{n} \cdot \ln \left(\frac{\sigma_{n-1, n, F \max \delta}}{s_{n-1, n, r e l}}\right)}
\end{aligned}
$$

$$
\begin{aligned}
\varepsilon_{n n, F \max }= & \varepsilon_{n-1, n, F \max } \cdot\left(\frac{n_{p n}}{1-n_{n-1}}\right)^{d_{n}+e_{n} \cdot \ln \varepsilon_{n-1, n, F \max }} . \\
& \left(1-v_{f n}\right)^{f_{n}+g_{n} \cdot \ln \varepsilon_{n-1, n, F \max }}
\end{aligned}
$$

$$
\begin{aligned}
A_{n n, F \max }= & A_{n-1, n, F \max } \cdot\left(\frac{n_{p n}}{1-n_{n-1}}\right)^{d_{n}+e_{n} \cdot \ln \sigma_{n-1, n, F \max }} . \\
& \left(1-v_{f n}\right)^{f_{n}+g_{n} \cdot \ln \varepsilon_{n-1, n, F \max }}
\end{aligned}
$$

Equations (29)-(32) should serve for the system containing 1 matrix (binder) and $n-1$ kinds of filler. $\delta$ should express relationship between the last included filler and binder component of matrix (Eqs. (29)-(30)). If the objective amount of porosity is not changed by the nth filler addition, then is valid the equality $n_{p n}=1-n_{n-1}$. It leads to simplification of the Eqs. (29)-(32).

\section{References}

1. Choren JA, Heinrich SM, Silver-Thorn MB (2013) Young's modulus and volume porosity relationships for additive manufacturing applications. J Mater Sci 48:5103-5112. https://doi.org/10.1007/ s10853-013-7237-5

2. Fan X, Case ED, Ren F, Shu Y, Baumann MJ (2012) Part II: fracture strength and elastic modulus as a function of porosity for hydroxyapatite and other brittle materials. J Mech Behav Biomed Mater 8:99-110. https://doi.org/10.1016/j.jmbbm .2011.12.014

3. Karthikeyan S, Balasubramanian V, Rajendran R (2014) Developing empirical relationships to estimate porosity and Young's modulus of plasma sprayed YSZ coatings. Appl Surf Sci 296:3146. https://doi.org/10.1016/j.apsusc.2014.01.021

4. Kovacik J (1999) Correlation between Young's modulus and porosity in porous materials. J Mater Sci Lett 18:1007-1010. https://doi.org/10.1023/A:1006669914946

5. Kovacik J (2008) Correlation between elastic modulus, shear modulus, Poisson's ratio and porosity in porous materials. Adv Eng Mater 10:250-252. https://doi.org/10.1002/adem.20070 0266

6. Smolin LY, Eremin MO, Makarov MP, Evtushenko EP, Kulkov SN, Buyakova SP (2014) Brittle porous material mesovolume structure models and simulation of their mechanical properties. AIP Conf Proc 1623:595-598. https://doi.org/10.1063/1.4899015

7. Grabenhorst J, Aneziris CG, Schaffoner S (2014) Influence of porosity on Young's modulus of carbon-bonded alumina from room temperature up to $1450^{\circ} \mathrm{C}$. Ceram Int 40:14439-14445. https://doi.org/10.1016/j.ceramint.2014.07.013

8. Zhang L, Gao KW, Elias A, Dong ZG, Chen WX (2014) Porosity dependence of elastic modulus of porous $\mathrm{Cr}_{3} \mathrm{C}_{2}$ ceramics. Ceram Int 40:191-198. https://doi.org/10.1016/j.ceramint.2013.05.122 
9. Kovacik J (2001) Correlation between shear modulus and porosity in porous materials. J Mater Sci Lett 20:1953-1955. https:// doi.org/10.1023/A:1013186702962

10. Sapozhnikov SB, Kudryavtsev OA, Dolganina NY (2015) Experimental and numerical estimation of strength and fragmentation of different porosity alumina ceramics. Mater Des 88:1042-1048. https://doi.org/10.1016/j.matdes.2015.08.117

11. Wu Z, Sun LC, Wang JY (2016) Synthesis and characterization of porous $\mathrm{Y} 2 \mathrm{SiO} 5$ with low linear shrinkage, high porosity and high strength. Ceram Int 42:14894-14902. https://doi.org/10.1016/j. ceramint.2016.06.128

12. Palchik V (1999) Influence of porosity and elastic modulus on uniaxial compressive strength in soft brittle porous sandstones. Rock Mech Rock Eng 32:303-309. https://doi.org/10.1007/s0060 30050050

13. Krishna V, Bose S, Bandyopadhyay A (2007) Low stiffness porous Ti structures for load-bearing implants. Acta Biomater 3:9971006. https://doi.org/10.1016/j.actbio.2007.03.008

14. Rubshtein AP, Trakhtenberg IS, Makarova EB, Triphonova EB, Bliznets DB, Yakovenkova LI, Vladimirov AB (2014) Porous material based on spongy titanium granules: Structure, mechanical properties, and osseointegration. Mater Sci Eng C Mater Biol Appl 35:363-369. https://doi.org/10.1016/j.msec.2013.11.020

15. Lian C, Zhuge Y, Beecham S (2011) The relationship between porosity and strength for porous concrete. Constr Build Mater 25:4294-4298. https://doi.org/10.1016/j.conbuildma t.2011.05.005

16. Sonnenschein MF (2003) Porosity-dependent Young's modulus of membranes from polyetherether ketone. J Polymer Sci B Polymer Phys 41:1168-1174. https://doi.org/10.1002/polb.10473

17. Gibson LJ, Ashby MF, Easterling KE (1988) Structure and mechanics of the iris leaf. J Mater Sci 23:3041-3048. https://doi. org/10.1007/BF00551271

18. Nielsen LF (1984) Elasticity and damping of porous materials and impregnated materials. J Am Ceram Soc 67:93-98. https:// doi.org/10.1111/j.1151-2916.1984.tb09622.x

19. Drozdov AD, Christiansen JC (2019) The effect of porosity on elastic moduli of polymer foams. J App Polym Sci 137:48449. https://doi.org/10.1002/app.48449

20. Prasad A, Fotou G, Li S (2013) The effect of polymer hardness, pore size and porosity on the performance of thermoplastic polyurethane-based chemical mechanical polishing pads. Mater Res Soc 28:2380-2393. https://doi.org/10.1557/jmr.2013.173

21. Hong-Liang D, Chao M, Yan-Di R (2016) Anisotropy of the elastic modulus for hybrid composites reinforced by short fibers and particles with respect to material porosity. J Appl Polym Sci. https://doi.org/10.1002/app.43708

22. Chen XD, Wu SX, Zhou JK (2013) Influence of porosity on compressive and tensile strength of cement mortar. Constr Build Mater 40:869-874. https://doi.org/10.1016/j.conbuildma t.2012.11.072

23. Hakim SA, Donaldson SL, Meyendorf GN, Browning CE (2017) Porosity effects on interlaminar fracture behavior in carbon fiber-reinforced polymer composites. Mater Sci App 8:170-187. https://doi.org/10.4236/msa.2017.82011

24. Antartis D, Dillon S, Chasiotis I (2015) Effect of porosity on electrochemical and mechanical properties of composite Li-ion anodes. J Compos Mater 49:1849-1862. https://doi. org/10.1177/0021998314568653

25. Sadasivuni KK, Cabibiha JJ, Deshmukh K, Goutham S, Abubasha MK, Gogoi JP, Klemenoks I, Sakale G, Sekhar BS, Sreekanth PSR, Rao KV, Knite M (2018) A review on porous polymer composite materials for multifunctional electronic application. Polym Plast Technol Eng 58:1253-1294. https://doi.org/10.1080/03602 559.2018.1542729

26. Gunathilake TMSU, Ching YC, Ching KY, Chuah $\mathrm{CH}$, Abdullah LC (2017) Biomedical and microbiological applications of biobased porous materials: a review. Polymers 9:160. https://doi. org/10.3390/polym 9050160

27. Cerny M, Jancar J (2017) Composites based on polyurethaneurea and ground rubber from car tyres: relation between structure and properties. Chem Pap 71:1119-1127. https://doi. org/10.1007/s11696-016-0060-0

28. Bhat MR, Binoy MP, Surya NM, Murthy CRL, Engelbart RW (2012) Non-destructive evaluation of porosity and it effect on mechanical properties of carbon fiber reinforce polymer composite materials. AIP Conf Proc 1430:1080-1087. https://doi. org/10.1063/1.4716341

Publisher's Note Springer Nature remains neutral with regard to jurisdictional claims in published maps and institutional affiliations. 